\title{
AN ASSESSMENT OF ENERGY EXPENDITURE OF SOLDIERS SERVING IN THE POLISH CHEMICAL UNITS, PERFORMING TRAINING TASKS IN 2 TYPES OF PERSONAL CHEMICAL PROTECTIVE CLOTHING - COMPARATIVE STUDIES
}

\author{
JERZY BERTRANDT ${ }^{1}$, ANNA KŁOS ${ }^{1}$, ROMAN ŁAKOMY ${ }^{1}$, and BARTOSZ BERTRANDT ${ }^{2}$ \\ ${ }^{1}$ Military Institute of Hygiene and Epidemiology, Warsaw, Poland \\ Laboratory of Food and Nutrition Hygiene \\ ${ }^{2}$ Military Research and Development Center, Warsaw, Poland \\ Laboratory of Food Research
}

\begin{abstract}
Objectives: Individual protection against contamination is the kind of protection provided to persons in an environment contaminated with radioactive substances, and war toxic or biological agents, including the use of gas masks, and insulating or filtration skin protection agents. The aim of this work was to perform a comparative assessment of energy expenditure of chemical troop soldiers wearing L-2 insulating personal protective clothes (PPC) and FOO-1 filter-sorptive PPC during training in the training ground conditions. Surveys on the subjective assessment of comfort related to using the L-2 and FOO-1 PPC were carried out as well. Material and Methods: A total of 29 men doing the same training tasks, wearing the L-2 PPC and FOO-1 filter-sorptive protective clothing with an MP-5 filter gas mask, underwent the examination. Measurements of energy expenditure values were done based on the frequency of heart contractions, recorded by the Polar Sport Tester 810 heart rate monitor. Results: It was found that an average energy expenditure of soldiers, resulting from performing training tasks, was lower among the subjects wearing the FOO-1 filter-sorptive PPC, compared to the energy load of the ones using the L-2 PPC. Conclusions: According to Christensen's classification of work severity, the average energy expenditure makes it possible to qualify works performed by soldiers using both types of PPC to moderate work. In the opinion of the examined soldiers serving in the chemical troops, the FOO-1 filter-sorptive PPC increases the sense of security while on a threatened ground. The FOO-1 filter-sorptive PPC is assessed by chemical troop soldiers as better because it hinders tasks fulfillment to a lesser extent. Int J Occup Med Environ Health. 2019;32(5):645-52
\end{abstract}

Key words:

chemical troops, chemical weapon, chemical and personal protective clothing, defense against CBRN hazards, NBC protection, energy expenditure

Received: August 31, 2018. Accepted: June 14, 2019.

Corresponding author: Jerzy Bertrandt, Military Institute of Hygiene and Epidemiology, Laboratory of Food and Nutrition Hygiene, Kozielska 4, 01-163 Warsaw, Poland (e-mail: jbertrandt@wihe.waw.pl). 


\section{INTRODUCTION}

Due to a high level of industrialization of the modern world, man is exposed to chemical substances and dangerous preparations in the workplace in all sectors of the economy.

The overriding aim of the state's activities in the field of internal security is to maintain the ability to react in the case of a wide variety of security threats, including natural disasters, other disasters, technical failures or terrorist attacks. There are many situations where workers are required to wear personal protective clothing (PPC), to protect themselves against certain primary hazards, such as heat or chemicals. However, PPC can also create ergonomic problems and there are important side effects which typically increase with the protection requirements becoming more stringent.

A wide range of threats and their expected consequences have resulted in a variety of tasks imposed on the armed forces, such as the monitoring of radioactive, chemical and biological contamination in the country. Chemical troops are the kind of troops intended to fulfill these specialist tasks. Chemical weapon is an element posing general military threat in the case of armed conflicts or terrorist attacks. The following tasks are included in the chemical troops' activities in combat conditions: monitoring chemical contamination spread and carrying out sanitary treatment of soldiers, along with disinfection of their uniforms, fighting equipment, or roads. The chemical troops' tasks in crisis situations include: participating in the monitoring of exposure to chemical contamination in the case of an uncontrolled release of hazardous chemicals to the environment, or interacting with rescue units in removing the consequences of chemical accidents. Therefore, individual protection against chemical contamination is a very important and still developed issue. It acquires particular significance when there is a need to carry out actions on a polluted ground. This also concerns training and other activities performed by soldiers from chemical troops, or rescue operations carried out by lifesavers from the State Fire Service in the field of chemical rescue.

Individual protection against contamination is the kind of protection provided to persons in an environment contaminated with radioactive substances, and war toxic or biological agents, including the use of gas masks, and insulating or filtration skin protection agents.

In order to ensure adequate protection and to maintain the continuity of operational capability, soldiers are equipped with suitable equipment protecting them against various effects of nuclear, biological and chemical (NBC) substances. Personal protective equipment against contamination provides each soldier with protection, enabling them to survive an attack of mass destruction weapons and to conduct combat operations [1]. The technical and operational parameters of individual chemical protection equipment significantly influence the possibilities and ways to carry out actions. It is desirable that the chemical protection equipment provide unlimited protection and strain the user's body to the lowest possible extent [2]. Personal NBC protective clothing which is used by the Polish Army is divided into insulation and filter-sorptive clothing. Currently, the Polish Army soldiers are equipped with 2 types of PPC, i.e., L-2 and FOO-1. The L-2 personal protective clothing creates an impermeable barrier for chemical, biological and radioactive agents [3]. It is a 1-piece light protective suit made of rubber-coated impregnated cotton fabric, khaki-colored. It is designed to protect skin against chemical and biological combat agents.

In recent years, the use of insulating clothing has been decreasing in favor of the use of filter-sorptive clothes that make it more comfortable to perform tasks under threat of contamination and in a polluted (infected) area. The FOO-1 filter-sorptive PPC, along with the MP-5 filter gas-mask, is designed to protect soldiers against chemical, biological or radioactive contamination occurring in the air, in the form of vapor, aerosols and dust. The clothing 
replaces, in air temperature above $5^{\circ} \mathrm{C}$, the standard field uniform and can be worn directly on the skin or underwear. In lower temperatures, it should be put on a tracksuit or directly on the field uniform. The NO-1 protective coat is a part of the FOO-1 filter-sorptive protective clothing. It is intended to protect soldiers against poisonous chemical weapon drops. The coat allows the soldier to leave or cross the contaminated zone and to fulfill combat tasks [4]. The aim of this work was to perform a comparative assessment of energy expenditure of chemical troop soldiers wearing the L-2 insulating PPC and the FOO-1 filter-sorptive PPC during training in the training ground conditions. Surveys on the subjective assessment of comfort related to using the L-2 and FOO-1 PPC were carried out as well.

\section{MATERIAL AND METHODS}

A total of 29 men doing the same training tasks, wearing the L-2 PPC and FOO-1 filter-sorptive protective clothing with an MP-5 filter gas mask, underwent the examination. Measurements of energy expenditure values were done based on the frequency of heart contractions, recorded by the Polar Sport Tester 810 heart rate monitor [5,6]. The energy expenditure value was calculated on the basis of the relationship between the frequency of heart contraction and oxygen consumption. The final result of the energy expenditure value, associated with the performed activity, was an average value from a minimum of 3 measurements. In addition, the nutritional status of all the subjects was assessed using anthropometric methods. The body mass and body height, as well as the thickness of 4 selected skin folds, were determined. The body mass and body height values were the basis for the body mass index (BMI) calculation, while the thickness of skin folds was the starting point for calculating the percentage fat content and lean body mass [7].

The approval of the Bioethics Committee at the Military Institute of Hygiene and Epidemiology in Warsaw was obtained for conducting the research.
The obtained results were subjected to statistical analysis using the Statistica 6 software. The statistically significant differences between the groups of subjects were determined at the significance level of $\leq 0.05$.

\section{RESULTS}

The mean age of the examined soldiers was $28.5 \pm 4.5$ years. The anthropometric indicator values are presented in Table 1.

The BMI values indicated that the subjects were slightly overweight (a norm up to $24.9 \mathrm{~kg} / \mathrm{m}^{2}$ ). Overweight was found among $39.3 \%$ of the examined soldiers while obesity concerned $7.1 \%$ of them. The percentage fat content was normal. The minimum overweight was probably a muscle overweight.

The examined soldiers performed training tasks provided by the training agenda. Training time was $8 \mathrm{~h}$ with a $30 \mathrm{~min}$ break for lunch.

The energy expenditure values during the same actions carried out in the L-2 insulating protective clothing and in the FOO-1 filter-sorptive protective clothing are presented in Table 2.

Table 1. Anthropometric indicators of the examined soldiers $(\mathrm{N}=29)$ trained in field conditions in the summer of 2016

\begin{tabular}{lcc}
\hline \multicolumn{1}{c}{ Variable } & M \pm SD & Min.-max \\
\hline Age [years] & $28.5 \pm 4.5$ & $21-40$ \\
Height [cm] & $177.4 \pm 6.6$ & $164.9-191.0$ \\
Body mass [kg] & $79.4 \pm 11.7$ & $64-111.9$ \\
Arm circumference [cm] & $33.3 \pm 3.9$ & $27.5-44.0$ \\
Skin-fold [mm] & & \\
$\quad$ biceps & $3.1 \pm 0.65$ & $2.0-4.2$ \\
$\quad$ triceps & $3.44 \pm 0.75$ & $2.2-5.0$ \\
$\quad$ under scapula & $15.8 \pm 4.2$ & $8.2-23.4$ \\
$\quad$ over iliac & $21.7 \pm 6.1$ & $9.6-33.4$ \\
BMI [kg/m²] & $25.1 \pm 2.8$ & $21-33.1$ \\
Fat content [\%] & $17.9 \pm 2.8$ & $10.2-22.3$ \\
Lean body mass & $64.9 \pm 9.1$ & $52.1-91.1$ \\
\hline
\end{tabular}


Table 2. Energy expenditure of the examined soldiers $(\mathrm{N}=29)$ trained in field conditions in the summer of 2016, and performing the same tasks in 2 types of protective clothing

\begin{tabular}{|c|c|c|}
\hline \multirow{2}{*}{ Activity } & \multicolumn{2}{|c|}{$\begin{array}{l}\text { Energy expenditure } \\
{\left[\begin{array}{c}\mathrm{kcal} / \mathrm{min}] \\
(\mathrm{M} \pm \mathrm{SD})\end{array}\right.}\end{array}$} \\
\hline & $\begin{array}{l}\text { L-2 insulating } \\
\text { PPC }^{\text {a }}\end{array}$ & $\begin{array}{l}\text { FOO-1 filter- } \\
\text { sorptive PPC }\end{array}$ \\
\hline Samples taking (N-12) & $6.70 \pm 1.2$ & $5.65 \pm 1.0^{*}$ \\
\hline Patrol (N-26) & $5.62 \pm 1.7$ & $4.44 \pm 1.3$ \\
\hline \multicolumn{3}{|l|}{ Decontamination } \\
\hline of a road (N-6) & $4.84 \pm 0.8$ & $4.22 \pm 0.8$ \\
\hline of equipment (N-6) & $3.98 \pm 1.1$ & $4.17 \pm 1.4$ \\
\hline $\begin{array}{l}\text { Establishing a treatment } \\
\text { point (N-8) }\end{array}$ & $4.72 \pm 1.2$ & $3.38 \pm 1.0^{*}$ \\
\hline
\end{tabular}

a Average 5.41 \pm 1.2 .

${ }^{\mathrm{b}}$ Average $4.37 \pm 1.1$.

* Statistically significant difference $\mathrm{p} \leq 0.05$.

It was found that the average energy expenditure resulting from the fulfillment of training tasks was significantly lower among the soldiers wearing the FOO-1 filter-sorptive protective clothing, compared with the energy load of the soldiers using the L-2 insulating protective clothing. According to Christensen's classification of work severity, the mean value of energy expenditure makes it possible to qualify the work done by the soldiers wearing both types of protective clothing to the category of moderate work [8]. The energy expenditure examination during various training activities performed by the soldiers using both types of protective clothing was carried out as well. Energy expenditure measurements were done among 12 soldiers wearing the L-2 PPC during works related to decontamination of people, roads, cars and security posts. The energy expenditure values for the activities under examination are presented in Table 3.

The energy expenditure values for the L-2 PPC varied from $3.43 \mathrm{kcal} / \mathrm{min}$ to $7.45 \mathrm{kcal} / \mathrm{min}$. Works related to decontamination of people, cars and security posts, or to guard service, in accordance with Christensen's classification, should be included in the group of light works (2.5$5.0 \mathrm{kcal} / \mathrm{min}$ ) [8]. Works connected with decontamination

Table 3. Energy expenditure $(\mathrm{EE})$ and heart rate $(\mathrm{HR})$ of the examined soldiers $(\mathrm{N}=29)$ trained in field conditions in the summer of 2016 while wearing the protective clothing

\begin{tabular}{|c|c|c|c|c|}
\hline \multirow[t]{2}{*}{ PPC/Activity } & \multirow{2}{*}{$\begin{array}{c}\mathrm{EE} \\
{[\mathrm{kcal} / \mathrm{min}]} \\
(\mathrm{M} \pm \mathrm{SD})\end{array}$} & \multicolumn{3}{|c|}{$\begin{array}{c}\mathrm{HR} \\
{[\mathrm{bpm}]}\end{array}$} \\
\hline & & $\min$. & $\max$ & $\mathrm{M} \pm \mathrm{SD}$ \\
\hline L-2 protective clothing $(\mathrm{M} \pm \mathrm{SD})$ & $4.76 \pm 1.4$ & $62.3 \pm 17.9$ & $159.1 \pm 28.2$ & $96.5 \pm 7.7$ \\
\hline decontamination of people (N-12) & $3.43 \pm 1.2$ & 60 & 157 & $85.1 \pm 6.8$ \\
\hline service on a security post (N-8) & $3.73 \pm 1.4$ & 46 & 158 & $97.2 \pm 7.2$ \\
\hline guard service $(\mathrm{N}-22)$ & $4.08 \pm 1.1$ & 60 & 139 & $94.0 \pm 7.0$ \\
\hline decontamination of a car (N-6) & $4.20 \pm 1.2$ & 53 & 219 & $92.6 \pm 7.2$ \\
\hline service on the contaminated persons distribution point (N-8) & $5.04 \pm 1.4$ & 62 & 139 & $94.2 \pm 6.9$ \\
\hline decontamination of land (N-4) & $5.40 \pm 1.5$ & 70 & 162 & $103.1 \pm 10.2$ \\
\hline camouflage of a car $(\mathrm{N}-8)$ & $7.45 \pm 2.1$ & 85 & 140 & $109.4 \pm 8.6$ \\
\hline FOO-1 filter-sorptive protective clothing $(\mathrm{M} \pm \mathrm{SD})$ & $4.52 \pm 1.45$ & $62.7 \pm 18.3$ & $141 \pm 23.3$ & $92 \pm 10.4$ \\
\hline BRDM's (armored reconnaissance vehicle) driver (N-4) & $2.42 \pm 0.6$ & 53 & 125 & $77 \pm 7.8$ \\
\hline decontamination of a building (N-12) & $4.67 \pm 1.5$ & 64 & 137 & $94 \pm 8.3$ \\
\hline $\operatorname{march}(\mathrm{N}-22)$ & $5.43 \pm 1.7$ & 61 & 149 & $98 \pm 10.7$ \\
\hline Star truck driver (N-4) & $5.57 \pm 2.0$ & 73 & 155 & $100 \pm 14.7$ \\
\hline
\end{tabular}


of ground and at the contaminated persons distribution point should be included in the group of moderate ones (5.0-7.5 kcal/min).

The soldiers using the FOO-1 filter-sorptive PPC marched, decontaminated buildings or were drivers of the armored reconnaissance vehicle BRDM. Their energy expenditure values are presented in Table 3.

The amount of energy expenditure of a BRDM driver, and the works performed during building decontamination, should be included in the group of light works, while the energy expenditure value of a Star truck driver, together with marching, should be considered as moderate works.

The results of the survey on the subjective assessment of work, carried out in 2 types of protective clothing, are presented in Table 4.

Both the examined groups stated that protective clothing significantly affected their energy load and caused body temperature elevation. The duration of work in protective clothing was evaluated strongly in favor of the FOO-1 clothing. The survey results analysis has shown that the FOO-1 filter-sorptive protective clothing is seen by the soldiers as better. The provided responses suggest that working in this type of clothing causes less fatigue and provides a greater sense of security, compared to working in the L-2 insulation clothing. Based on the responses of the examined soldiers, the FOO-1 filter-sorptive protective clothing restricts movement to a lesser extent, and the duration of work in protective clothing was evaluated strongly in favor of the FOO-1 clothing.

\section{DISCUSSION}

There is not enough data on the impact of NBC personal protective clothing on the value of human energy expenditure in the available literature. The research results available in literature focus mainly on the assessment of thermal load associated with wearing personal protective clothing and comparisons of various types of such clothing. The energy load of soldiers resulting from working in NBC PPC is influenced by such factors as wearing a uniform, carrying personal weapon or using a complete set of chemical protective clothing, including boots, a gas mask and gloves.

Duggan showed that performing tasks by soldiers wearing chemical protective clothing increased the energy cost, significantly shortened the time of fatigue and, due to the increased production of metabolic heat, could increase the risk of overheating [9]. The results of research conducted in 1995 by Patton showed that the oxygen uptake $\left(\mathrm{VO}_{2}\right)$ values were significantly higher among the soldiers who marched wearing NBC protective clothing, in comparison with those wearing standard uniforms [10]. Also, studies by Dorman et al. revealed an increased metabolic cost of the soldiers, from 2.4 to $20.9 \%$, when walking and crossing the track in PPC, compared to performing the same activities while wearing typical uniforms. It was also shown that an increase in the metabolic rate by $2.7 \% / \mathrm{kg}$ of the increased mass of clothing during works required a larger range of movement in PPC, which might affect the body energy load [11].

The results of another research on the burden of men working in anti-chemical protective clothing in a hot environment indicated a significant thermal load and maximum cardiovascular load, as well as intense subjective discomfort. It forced the limitation of working in this protective clothing to $12 \mathrm{~min}$ [12]. In addition, the results of current research on the impact of NBC clothing on the energy load of soldiers have revealed a significantly higher physiological strain index value, in relation to performing work while wearing standard uniforms, amounting to $5.3 \pm 1.4$ and $2.32 \pm 0.42$, respectively. It has also been shown that NBC protective clothing can cause a greater physiological load, more restrictions on performance and early exhaustion, as compared to typical military uniforms. The use of NBC protective clothing increases body tem- 
Table 4. Subjective assessment of work comfort related to using 2 types of personal protective clothing (PPC) during all training tasks in field conditions in the summer 2016

\begin{tabular}{|c|c|c|}
\hline \multirow[t]{2}{*}{ Survey } & \multicolumn{2}{|c|}{$\begin{array}{c}\text { Respondents } \\
{[\%]} \\
(\mathrm{N}=29)\end{array}$} \\
\hline & L-2 insulating PPC & FOO-1 filter-sorptive PPC \\
\hline \multicolumn{3}{|l|}{ Do you feel fatigue and to what extent? } \\
\hline no & 9.1 & 4.5 \\
\hline little & 31.8 & 45.5 \\
\hline medium & 36.4 & 40.9 \\
\hline significant & 18.2 & 9.1 \\
\hline extreme & 4.5 & - \\
\hline \multicolumn{3}{|l|}{ Is the fatigue growing as time goes on? } \\
\hline yes & 86.4 & 90.9 \\
\hline no & 13.6 & 9.1 \\
\hline \multicolumn{3}{|c|}{$\begin{array}{l}\text { Do you think that protective clothing provides enough protection } \\
\text { in the polluted area? }\end{array}$} \\
\hline lack of security & 40.9 & 13.6 \\
\hline little & 27.3 & 31.8 \\
\hline medium & 31.8 & 36.4 \\
\hline significant & - & 18.2 \\
\hline sense of security & - & - \\
\hline \multicolumn{3}{|c|}{ How long can you work in protective clothing? } \\
\hline $0.5 \mathrm{~h}$ & 23.8 & 13.6 \\
\hline $1 \mathrm{~h}$ & 33.3 & 31.8 \\
\hline $2 \mathrm{~h}$ & 33.3 & 45.5 \\
\hline $4 \mathrm{~h}$ & 9.6 & 9.1 \\
\hline$\geq 6 \mathrm{~h}$ & - & - \\
\hline \multicolumn{3}{|c|}{ Does protective clothing restrict your movement? } \\
\hline no & - & 13.6 \\
\hline to a minor extent & 18.2 & 36.4 \\
\hline to a moderate extent & 40.9 & 27.3 \\
\hline to a large extent & 40.9 & 22.7 \\
\hline \multicolumn{3}{|c|}{ Does protective clothing affect the energy burden? } \\
\hline yes & 95.8 & 90.9 \\
\hline no & 4.2 & 9.1 \\
\hline \multicolumn{3}{|c|}{$\begin{array}{l}\text { Does protective clothing cause an increase in body temperature } \\
\text { and sweating? }\end{array}$} \\
\hline yes & 100.0 & 90.9 \\
\hline no & - & 9.1 \\
\hline
\end{tabular}


perature and reduces the individual time of tolerance and heat load [13].

The results of energy expenditure (EE) examinations related to the performance of tasks while wearing personal protective clothing showed that the average active EE among the participants was $475 \pm 142 \mathrm{kcal}$ during $2 \mathrm{~h}$ of exercise. Active EE was the energy spent doing the various chemical, biological, radiological and nuclear (CBRN) activities, including preparing for and concluding the activity. A rough estimate of the total daily EE was about $2420 \mathrm{kcal}$, calculated by adding an estimated active EE to an estimated resting EE ( 1920 kcal) [14].

The results of the physiological tolerance assessment of individual chemical protective clothing and equipment weighing $>35 \mathrm{~kg}$ in simulated extreme environmental conditions have shown that the physiological tolerance is not only affected by the external environmental factors but also by the workload. Cardiovascular stress is a factor limiting the tolerance when working in heavy multilayered PPC [15].

\section{CONCLUSIONS}

1. The average energy expenditure of soldiers resulting from performing training tasks was lower among the subjects wearing the FOO-1 filter-sorptive protective clothing, compared to the energy load of the ones using the L-2 personal protective clothing.

2. According to Christensen's classification of work severity, the average energy expenditure makes it possible to qualify works performed by the soldiers using both types of protective clothing to moderate work.

3. In the opinion of the examined soldiers serving in the chemical troops, the FOO-1 filter-sorptive protective clothing increases the sense of security while on threatened ground.

4. The FOO-1 filter-sorptive protective clothing is assessed by the chemical troop soldiers as better because it hinders tasks fulfillment to a lesser extent.

\section{REFERENCES}

1. [Order No. 332/Oper/P7 of the Chief of General Staff of the Polish Army. Defense against weapons of mass destruction in the combined operations (DD/3.8). MON;2004. Chem. 396/2004]. Polish.

2. Harmata W, Nyszko G. Respiration and skin - individual protection against contamination part. I. Saf Fire Tech. 2010;4:123-38.

3. Harmata W. Respiration and skin - individual protection against contamination part. II Bezp Tech Pożar. 2011;1:129-50.

4. Maciejewski P, Robak W, Młynarczyk M. Protection from CBRN Contamination in the Polish Armed Forces. Saf Fire Tech. 2015;1:107-18.

5. Polar Heart Rate Monitor S 810i [Internet]. 2017 [cited 2017 May 15]. Available from: https://support.polar.com/support_ files/en/C225742500419A8A42256CA0003E0D1A/179450\%20 MANUAL\%20S810i\%20USAGBR\%20A.pdf.

6. SAI Global Limited (AU) [Internet]. Polish Committee for Standardization. PN-EN ISO 8996:2005 Ergonomics of the thermal environment - Determining the metabolic rate. [cited 2017 May 15]. Available from: https:/infostore. saiglobal.com/en-gb/Search/Standard/?searchTerm=PN EN ISO 8996:2005.

7. Durnin J, Womersley J. Body fat estimate from total body density and its estimation from skinfold thickness. Brit J Nutr. 1974;23:77-97, https://doi.org/10.1079/BJN19740060.

8. Christensen CG, Frey HM, Foenstein EA. A critical evaluation of energy expenditure estimates based on individual consumption/heart rate curves and average daily heart rate. Am J Clin Nutr. 1983;37:468-72, https://doi.org/10.1093/ ajcn/37.3.468.

9. Duggan A. Energy cost of stepping in protective clothing ensembles. Ergonomics. 1988;311:3-11, https://doi.org/10.1080/ 00140138808966645.

10. Patton JF, Bidwell TE, Murphy MM, Mello RP, Harp ME. Energy cost of wearing chemical protective clothing during progressive treadmill walking. Aviat Space Envir MD. 1995;66:238-42. 
11. Dorman LE, Havenith G. The effects of protective clothing and its properties on energy consumption during different activities. Eur J Appl Physiol. 2009;105(3):463-70, https:// doi.org/10.1007/s00421-008-0924-2.

12. Ilmarinen R, Lindholm H, Koivistoinen K, Helistén P. Physiological evaluation of chemical protective suit systems (CPSS) in hot conditions. Int J Occup Saf Ergo. 2004;3:21526, https://doi.org/10.1080/10803548.2004.11076609.

13. Mehri NS, Ebadi A, Khoshnevis MA, Mohebbi HA. Effect of protective chemical garmenting on physiological strain index. Iran J Military Med. 2010;12(2):111-5.
14. Goetz V, Yokota M, Karis AJ, Tharion WJ. Energy expenditure and metabolic heat production storage estimates of tactical law enforcement personnel during chemical, biological, radiological, and nuclear (CBRN) training. Technical Report T11-05. U.S. Army Research Institute of Environmental Medicine - Natick 2011, https://doi.org/10.21236/ADA549510.

15. Costello JT, Stewart KL, Stewart IB. The effects of metabolic work rate and ambient environment on physiological tolerance times while wearing explosive and chemical personal protective equipment. Biomed Res Int. 2015; 2015, https:// doi.org/10.1155/2015/857536.

This work is available in Open Access model and licensed under a Creative Commons Attribution-NonCommercial 3.0 Poland License - http://creativecommons.org/ licenses/by-nc/3.0/pl/deed.en. 